\title{
Improvement of the Hydrogen Microprint Technique on AHSS Steels
}

\author{
J. A. Ronevich • J. G. Speer • G. Krauss • \\ D. K. Matlock
}

Received: 18 April 2012/ Accepted: 16 May 2012/Published online: 3 June 2012

(C) Springer Science+Business Media, LLC and ASM International 2012

\begin{abstract}
Preferential hydrogen diffusion paths in lowcarbon ferritic steel and transformation-induced plasticity (TRIP) steel characteristic of new advanced high strength sheet steels (AHSS) were evaluated via the hydrogen microprint technique (HMT). As a consequence of hydrogen diffusion and evolution from the sample after charging, the technique involves reduction of $\mathrm{AgBr}$ emulsion applied to the surface of a charged sample to produce discrete $\mathrm{Ag}$ grains which identify, via scanning electron microscope (SEM) imaging, locations where hydrogen evolved. Enhancements to the results are revealed through a newly developed image-before-etch HMT method, consisting of SEM imaging before and then again after etching. The modified technique was implemented to facilitate direct comparison of silver grains with the features of an etched multi-phase TRIP steel microstructure. Results from SEM imaging demonstrated the effectiveness of the imagebefore-etch method to avoid artifacts and to positively identify hydrogen evolution sites in AHSS TRIP steel microstructures.
\end{abstract}

Keywords Steel · Scanning electron microscope . Hydrogen permeation · Hydrogen embrittlement

J. A. Ronevich - J. G. Speer - G. Krauss - D. K. Matlock Department of Metallurgical and Materials Engineering, Advanced Steel Processing and Products Research Center, Colorado School of Mines, 1500 Illinois Street, Golden, CO 80401, USA

Present Address:

J. A. Ronevich ( $\square)$

Sandia National Laboratories, Livermore, CA 94550, USA

e-mail: jronevic@gmail.com; jaronev@sandia.gov

\section{Introduction}

Diffusible hydrogen, at levels as low as 1-2 ppm [1-3], in high strength steel has been documented to cause deleterious effects to mechanical properties. Therefore, to understand and possibly mitigate hydrogen embrittlement, significant effort has been focused on investigating paths by which hydrogen diffuses through steel. Hydrogen is the smallest element and accordingly it has extremely fast diffusion rates in ferrite at room temperature, e.g., $10^{-5} \mathrm{~cm}^{2} / \mathrm{s}$ [2], which makes many methods of observing hydrogen very difficult. In contrast, room temperature hydrogen diffusion in austenite has been reported to be significantly slower, $\approx 10^{-12} \mathrm{~cm}^{2} / \mathrm{s}[4]$.

A unique method that has been used to identify the location of hydrogen evolution at a steel surface is the hydrogen microprint technique (HMT) [5, 6]. This technique utilizes the reduction of $\mathrm{AgBr}$, coated on the surface, to produce silver grains observable in a scanning electron microscope (SEM) and then correlated to the location of hydrogen. Ovejero-Garcia [6] first developed the technique; however, many modifications have been incorporated by Ichitani et al. [7] to increase the detection efficiency of the method.

The procedure developed by Ovejero-Garcia [6] involved charging polished steel, application of a $\mathrm{AgBr}$ emulsion, and exposure to allow the hydrogen to evolve out of the steel and react with the emulsion. After exposure, photographic fixing removed unreacted $\mathrm{AgBr}$ crystals and the remaining silver particles mapped the locations where hydrogen exited the steel surface. Much of the previous work using HMT was performed on coarse-grained steels that were primarily ferrite. The large grain size (typically $>10 \mu \mathrm{m}$ ) made for easy interpretation of the silver distributions and consequently hydrogen locations resulting 
from grain boundary or bulk diffusion $[6,8,9]$. However, application of this technique to multi-phase finer-grained steels necessitates more precise spatial identification of phases to properly determine hydrogen locations with respect to the microstructure.

Advances in the HMT methodology made by Ichitani et al. [5, 7] include etching the steel prior to applying the emulsion coating. Etching provided a means to identify the location of silver with respect to microstructural features. It was also found that electroplating a very thin nickel coating on the etched surface enhanced the detection efficiency by assisting ionization of hydrogen atoms. In addition to nickel plating, the emulsion was exposed to elevated humidity levels to enhance detection efficiency. It was found that at relative humidity levels $>80 \%$, water facilitated the transfer of ionic species. Applying these modifications, detection efficiencies were reported at $40 \%$, meaning four out of every ten hydrogen atoms permeating the steel resulted in observed reduction of silver [7].

With significant research today in development of advanced high strength steel (AHSS), there is greater interest in hydrogen interactions with steels that have strength levels above $1000 \mathrm{MPa}$ and that consist of multiphase microstructures with refined constituents, often $1-2 \mu \mathrm{m}$. Therefore, it is the purpose of this paper to discuss the development of a new image-before-etch method used to identify hydrogen evolution sites with respect to fine microstructures. Secondly, a transformation-induced plasticity (TRIP) steel, characteristic of AHSS, was selected to assess the applicability of the new HMT method in determining hydrogen evolution sites.

\section{Materials and Methods}

\section{Fundamentals of the HMT}

A monolayer of liquid emulsion containing $\mathrm{AgBr}$ is coated onto steel [7]. After hydrogen diffuses through the microstructure, it exits the steel and reduces the $\mathrm{Ag}^{+}$to $\mathrm{Ag}^{0}$ as shown in Eq. 1 [8]

$\mathrm{AgBr}+1 / 2 \mathrm{H}_{2}=\mathrm{Ag}^{0}+\mathrm{H}^{+}+\mathrm{Br}^{-}$.

Spatial resolution of the silver grains in SEM imaging has been reported as low as $0.1 \mu \mathrm{m}$ [5]. A schematic representation of the reduction of $\mathrm{Ag}^{+} \rightarrow \mathrm{Ag}^{0}$ as described above is shown in Fig. 1 [5].

\section{Material}

Two sheet steels, recently studied in papers focused on hydrogen embrittlement of AHSS [3,11], were examined in this study: TRIP steel with thickness of $1.2 \mathrm{~mm}$ and

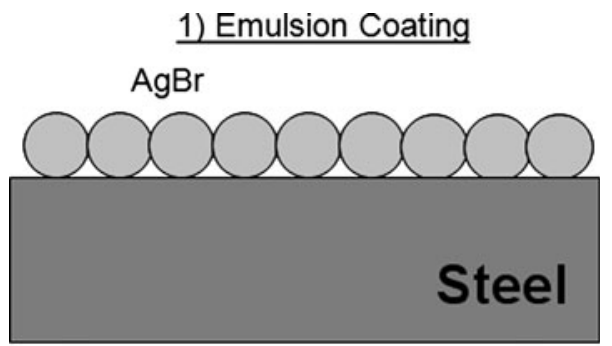

2) Reduction of $\mathrm{Ag}$ ions

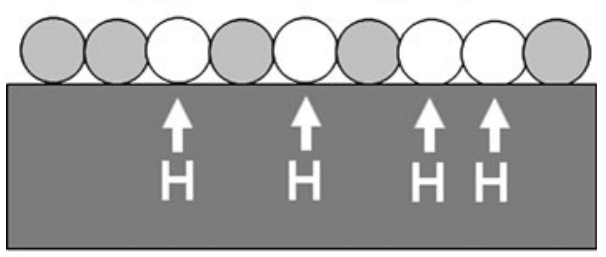

3) Fixing removes unreacted $\mathrm{AgBr}$

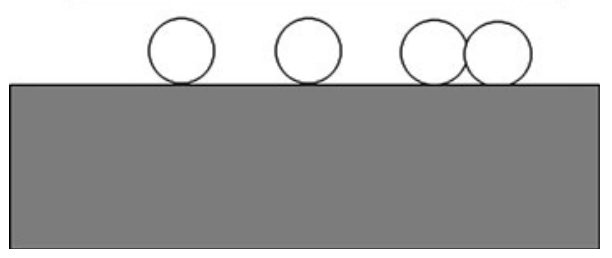

Fig. 1 Schematic of HMT (modified from [10]). (1) AgBr emulsion is coated on polished steel. (2) As $\mathrm{H}$ atoms evolve out of steel, reduction of $\mathrm{Ag}^{+}$to $\mathrm{Ag}$ occurs on surface. (3) Fixing removes unreacted $\mathrm{AgBr}$ crystals and reveals $\mathrm{Ag}$ grains where $\mathrm{H}$ evolved from surface

low-carbon ferritic mild steel of $1.0 \mathrm{~mm}$. The chemical compositions of the two steels are shown in Table 1. In the TRIP steel microstructure, shown in Fig. 2(a), darker regions consist of $14.5 \%$ retained austenite (RA) (as measured by $\mathrm{x}$-ray diffraction) or martensite/austenite (M-A) and bainite, and light gray regions are polygonal ferrite, with an average intercritical ferrite (ICF) grain size of $\sim 3 \mu \mathrm{m}$. SEM imaging was used to identify the fine microstructural constituents of TRIP steel (in Fig. 2a) and are discussed in more detail below. RA films are on the order of $1 \mu \mathrm{m}$ thick or less. The low-carbon steel microstructure, Fig. 2(b), consists primarily of ferrite with an average grain size of $17 \mu \mathrm{m}$, and a low volume fraction of grain boundary cementite.

\section{Hydrogen Charging and HMT Testing}

Coupons $(20 \mathrm{~mm} \times 20 \mathrm{~mm} \times$ sheet thickness $)$ were cathodically charged at $5 \mathrm{~mA} / \mathrm{cm}^{2}$ in a $1 \mathrm{~N} \mathrm{H}_{2} \mathrm{SO}_{4}+$ $1 \mathrm{mg} / \mathrm{L} \mathrm{As}_{2} \mathrm{O}_{3}$ electrolyte for $80 \mathrm{~min}$. During charging, the electrolyte was only in contact with one side of the sheet steel, thus promoting unidirectional diffusion of hydrogen. Prior to charging, the steel surface in contact with the electrolyte was ground to 600 grit and the opposing side 
Table 1 Chemical compositions of TRIP and low-carbon steels (wt.\%)

\begin{tabular}{lllllllllllll}
\hline Material & $\mathrm{C}$ & $\mathrm{Mn}$ & $\mathrm{Si}$ & $\mathrm{Ni}$ & $\mathrm{Cr}$ & $\mathrm{Mo}$ & $\mathrm{Ti}$ & $\mathrm{Al}$ & $\mathrm{N}$ & $\mathrm{S}$ \\
\hline TRIP & 0.19 & 1.59 & 1.63 & 0.02 & 0.03 & 0.01 & 0.003 & 0.036 & 0.011 & 0.002 & 0.013 \\
Low carbon & 0.035 & 0.19 & $\ldots$ & $\ldots$ & $\ldots$ & $\ldots$ & $\ldots$ & 0.045 & $\ldots$ & 0.014 & 0.011 \\
\hline
\end{tabular}

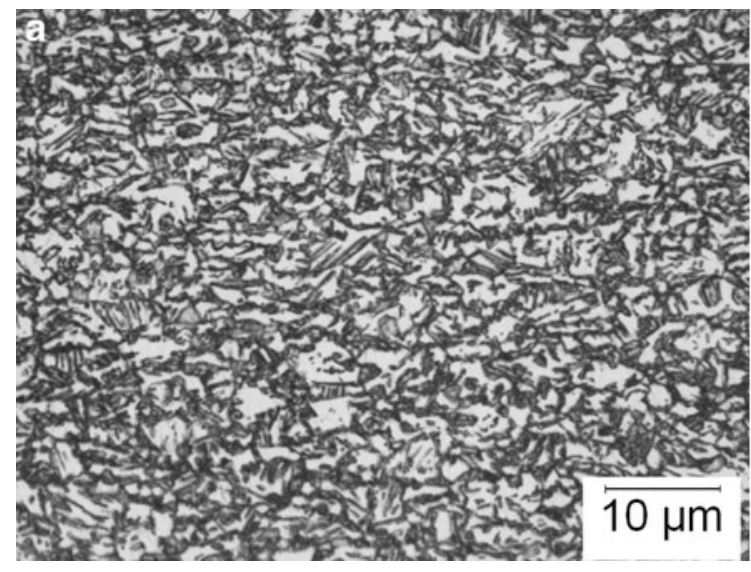

Fig. 2 a TRIP steel microstructure; white regions are ferrite, dark regions are RA, bainite, or M-A constituents (confirmed with XRD and SEM images). b Low-carbon steel microstructure with average

open to atmosphere was polished to $1 \mu \mathrm{m}$. These surfaces are referred to, respectively, as "ground" and "polished". A protective plastic film was placed on the $1 \mu \mathrm{m}$ polished side to prevent contact with the electrolyte. After hydrogen charging, the plastic film was removed and the sample was cleaned with distilled water and ethanol to remove any acid. The $\mathrm{AgBr}$ emulsion, formed by diluting $10 \mathrm{~g}$ of Ilford L-4 $\mathrm{AgBr}$ gel into $20 \mathrm{~mL}$ of $1.4 \mathrm{~mol} / \mathrm{L} \mathrm{NaNO} \mathrm{N}_{2}[5,7]$, was then applied to the polished side via a wire-loop method [6] with a wire diameter of $\sim 0.3 \mathrm{~mm}$ and a loop diameter of $\sim 38 \mathrm{~mm}$. The wire loop was submerged in an emulsion slurry, and on removal a thin slurry film, held in place by surface tension, was suspended within the loop (i.e., similar to a ring and soap bubble). The loop was then dropped over the top of the steel sample, depositing a uniform emulsion layer on the surface for analysis. Time between removal from the charging set-up and application of $\mathrm{AgBr}$ emulsion was 3-4 min. The emulsion was then allowed to dry for 3 min, forming a gel, and was placed for $1 \mathrm{~h}$ in a humidified chamber, with the relative humidity $>80 \%$. Elevated humidity facilitated transfer of ionic species and prevented the emulsion from drying and cracking, which would allow areas for hydrogen to escape without reacting with the $\mathrm{AgBr}$ [7]. This treatment was conducted in a dark room to prevent any reduction of silver bromide by light [12]. During the $1 \mathrm{~h}$ exposure, hydrogen evolved out of the steel and reduced the $\mathrm{AgBr}$ to $\mathrm{Ag}$ through the reaction described in Eq. 1 [7]. Following the $1 \mathrm{~h}$ exposure, the steel was placed in a formalin solution for $3 \mathrm{~s}$ to prevent

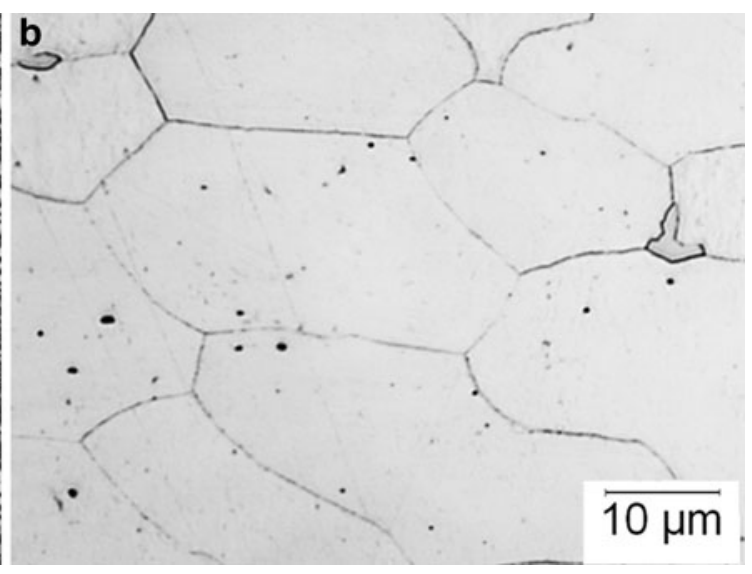

ferrite grain size of $17 \mu \mathrm{m}$ (light optical micrographs of longitudinal cross sections, $2 \%$ nital etch)

redistribution of silver grains followed immediately by $10 \mathrm{~min}$ in $0.60 \mathrm{~mol} / \mathrm{L} \mathrm{Na}_{2} \mathrm{~S}_{2} \mathrm{O}_{3}$ (to remove the unreacted $\mathrm{AgBr}$ crystals) diluted with $1.4 \mathrm{~mol} / \mathrm{L} \mathrm{NaNO}_{2}$ (to prevent corrosion of the steel) [5].

Two methods, identified here as image-after-etch and image-before-etch, were applied with respect to the sequence of SEM imaging and etching. In the image-afteretch method, etching of the polished surface was performed prior to hydrogen charging and application of $\mathrm{AgBr}$ emulsion. Therefore, following photographic fixing, SEM images were taken of silver grains on an etched microstructure. In the image-before-etch method, steel was hydrogen charged, emulsion was applied to the polished surface, and SEM images were taken of silver grains on the polished surface. Surfaces were then cleaned, etched with $2 \%$ nital for $2 \mathrm{~s}$, and re-imaged. Fiducial marks were used to relocate the original positions and SEM images were recorded from the etched surface. The image-before-etch method facilitated direct comparison of the silver grains with respect to the etched microstructure.

\section{Results and Discussion}

Figure 3 shows an SEM image of the TRIP microstructure etched with $2 \%$ nital for $10 \mathrm{~s}$. RA and M-A constituents are preferentially elevated with respect to ICF, which is attacked preferentially by the nital [13]. The differences in topography are shown below to influence the HMT results. 
SEM images from HMT using the image-after-etch method, i.e., etched prior to charging, are shown in Fig. 4(a) for low-carbon steel and Fig. 4(b) for TRIP steel. The low-carbon steel, in Fig. 4(a), shows ubiquitous silver grains covering the grain boundaries and interior of grains, with no specific location preference. Silver grains were identified by energy dispersive spectroscopy (EDS) and are observed as white spheres. Observation of a homogeneous distribution of silver across grains and grain boundaries suggests that there is no preferential diffusion path of hydrogen through the steel. Similar results, with respect to silver locations, were reported in the literature for lowcarbon steels [5, 14]. Figure 4(b) shows the results from the image-after-etch method on TRIP steel in which silver grains were observed predominantly on austenitic regions, as shown in Fig. 3, were elevated with respect to the ferrite where negligible amounts of silver are apparent. The HMT

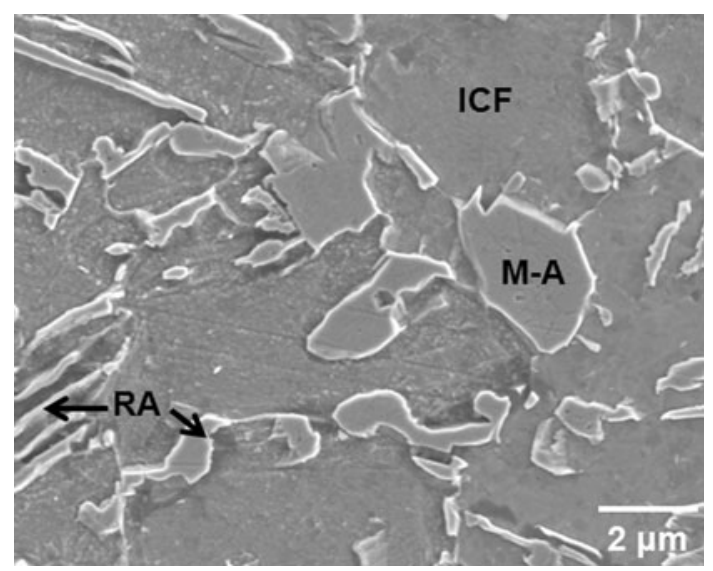

Fig. 3 SEM image of TRIP steel etched with $2 \%$ nital for $10 \mathrm{~s}$. ICF intercritical ferrite, $M-A$ martensite-austenite, $R A$ retained austenite. RA films and islands are on the order of $1 \mu \mathrm{m}$ or less
SEM image of etched TRIP steel in Fig. 4(b) gives the appearance that hydrogen diffused mainly through austenite as opposed to ferrite. This observation is contrary to predictions based on room temperature hydrogen diffusivities in ferrite and austenite reported in the literature, $10^{-5}$ and $10^{-12} \mathrm{~cm}^{2} / \mathrm{s}$ [2, 4], respectively. It was anticipated that as a consequence of the higher diffusivity in ferrite, more silver grains would be observed in the ferrite than in the austenite. Reasons for this discrepancy are discussed below. Figure 4 also shows that despite equal charging and exposure times, the quantity of silver grains is much greater on the low-carbon steel than on the TRIP steel. The latter observation could be due to the higher diffusivity of hydrogen in a fully ferritic microstructure and/or increased quantities of hydrogen evolving in the fixed exposure time due to the thinner gage of the low carbon steel (1.0 vs. $1.2 \mathrm{~mm}$ ).

Figure 5 presents SEM images of TRIP steel observable by HMT image-before-etch method. SEM images of hydrogen charged polished steel, covered with emulsion, and held for $1 \mathrm{~h}$ exposure are shown in Fig. 5(a) and (c) representing two regions of the same TRIP steel sample. Figure 5(b) and (d) shows the resulting SEM images of the same regions in (a) and (c) that were subsequently cleaned, etched with $2 \%$ nital for $2 \mathrm{~s}$ (to avoid significant removal of material), and re-imaged. Comparison of Fig. 5(b) and (d) with Fig. 3 shows similar microstructural features but with less surface relief, a consequence of the shorter nital etching times used for the images in Fig. 5. A comparison of Fig. 5(b) and (d) with (a) and (c) shows that the regions without silver in (a) and (c) correspond directly to the austenite and $\mathrm{M}-\mathrm{A}$ constituents revealed after etching. The observations in Fig. 5 are consistent with expectations based on hydrogen diffusivities, i.e., the concentrations of silver should be greatest in the constituent (i.e., ferrite)
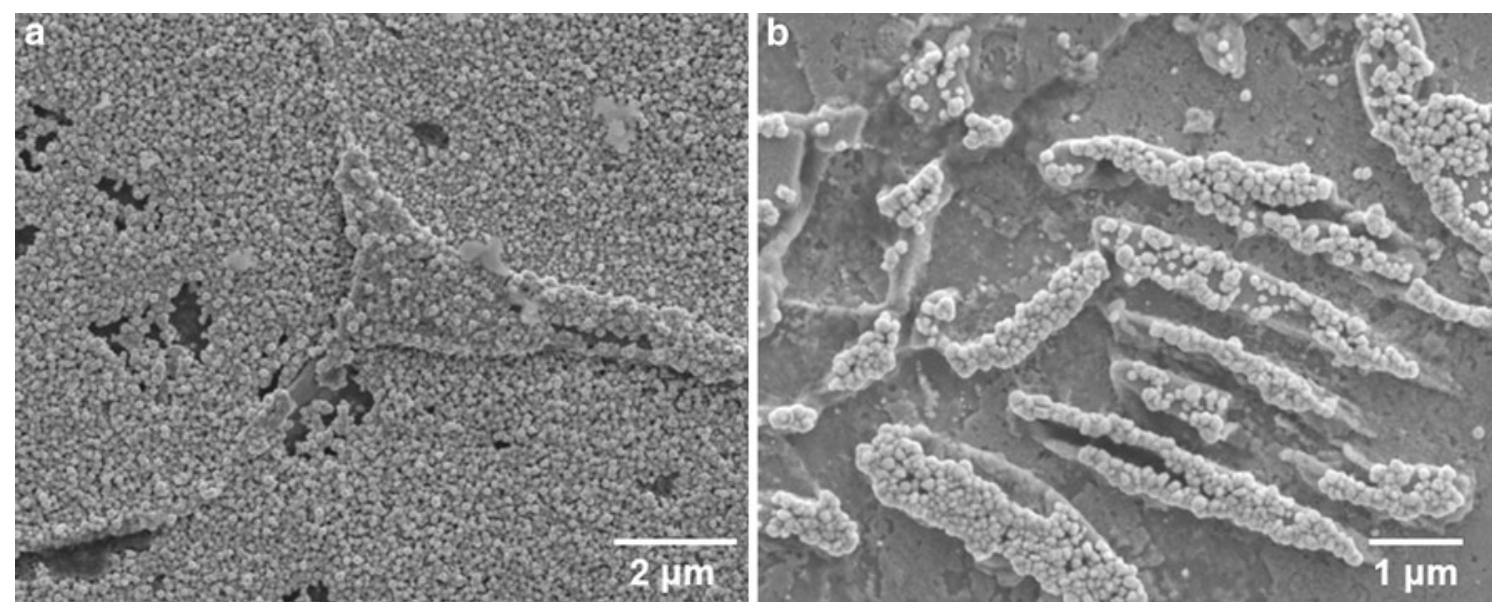

Fig. 4 HMT SEM images using image-after-etch method, i.e., etched before HMT of a low-carbon mild steel showing ubiquitous silver particles and $\mathbf{b}$ TRIP steel showing silver particles predominantly on austenite regions, i.e., elevated regions. (2\% nital) 

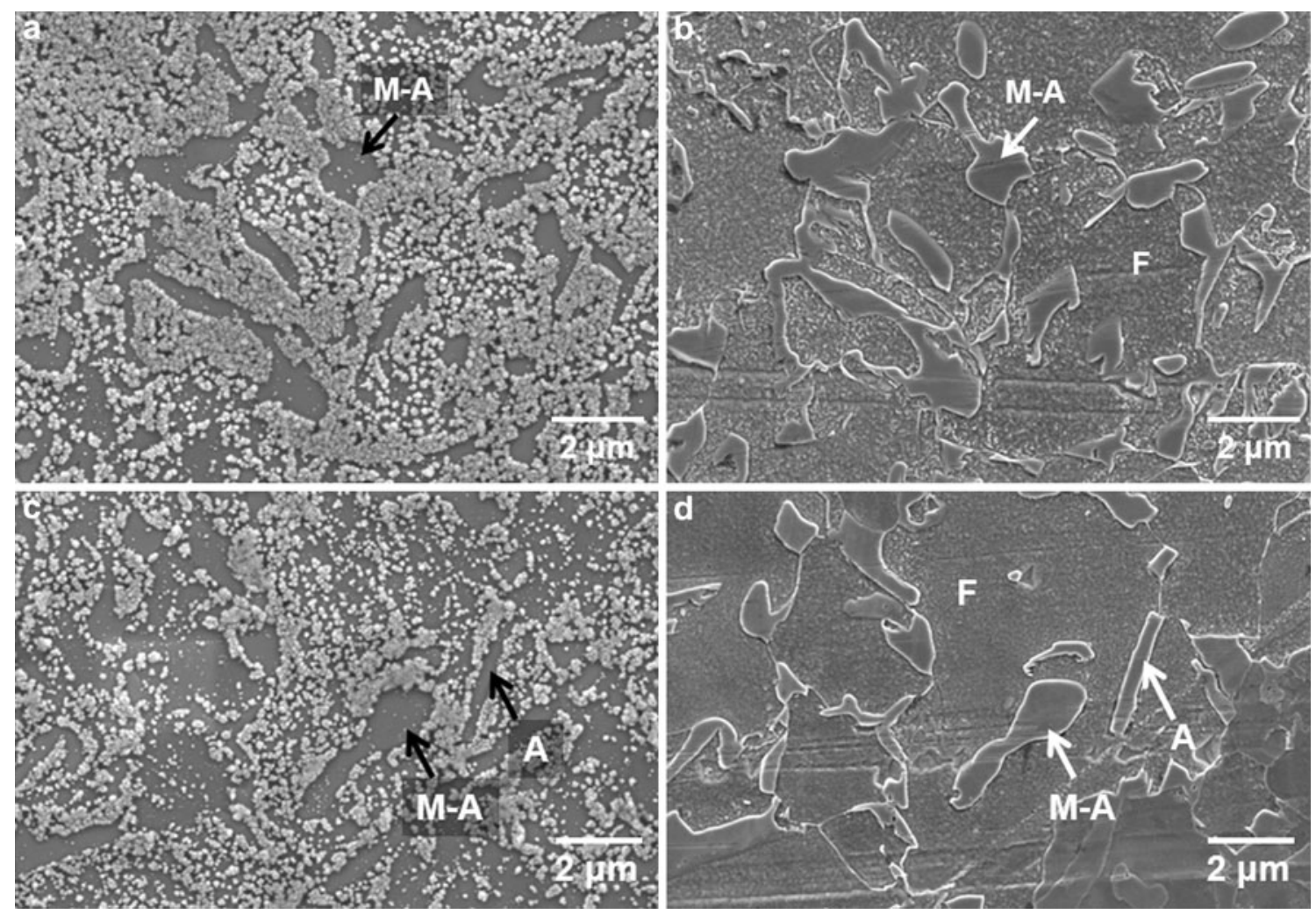

Fig. 5 SEM images of HMT from two regions of TRIP steel charged for $80 \mathrm{~min}$ using image-before-etch method. a, c Silver grains cover majority of unetched surface except small regions which were

identified as austenite or M-A constituents. b, $\mathbf{d}$ Cleaned and etched, with $2 \%$ nital for $2 \mathrm{~s}$, of (a) and (c), respectively

with the highest hydrogen diffusivity. Slightly elevated silver concentrations were observed in Fig. 5(a) and (c) near grain boundaries of austenite and ferrite or $\mathrm{M}-\mathrm{A}$ and ferrite indicating possibly greater diffusion paths. In comparison to the TRIP steel, application of the imagebefore-etch method to the low carbon steel produced an image identical to that for image-after-etch method in Fig. 4(a) in which silver grains uniformly covered the surface indicating no preferential diffusion path. Lower amounts of surface relief were expected to be present in the single-phase ferritic microstructure of the low-carbon steel, resulting in more uniform contact of the $\mathrm{AgBr}$ emulsion. Comparison of HMT images in Fig. 5(a) and (c) on polished samples with the corresponding HMT image on an etched sample (Fig. 4b) shows that the results are highly sensitive to sample preparation. The image-after-etch method, in which the sample was etched prior to applying the emulsion, apparently resulted in surface relief that prevented uniform contact of the emulsion to the etched surface. The resulting SEM images thus exhibited an artifact where the silver was associated with the elevated regions of austenite rather than the ferritic regions which evolved the hydrogen. One possible explanation for this phenomenon would be that hydrogen that evolved at

austenite-ferrite grain boundaries may have reduced the $\mathrm{AgBr}$ emulsion locally at sites which were in contact with the emulsion, i.e., austenite. In the image-before-etch method, the emulsion was applied to an unetched, flat surface and it was interpreted that more uniform contact of the emulsion with the surface occurred resulting in direct observance of the sites where hydrogen evolved from the steel surface.

The results from application of the two HMT methods revealed that fine TRIP microstructures, characteristic of AHSS, necessitate that the newly developed image-beforeetch method be used to positively identify hydrogen evolution sites in the microstructure. Using the image-beforeetch method, in which etching was performed after imaging of silver grains, SEM images revealed hydrogen evolution sites to be predominantly ferrite.

\section{Conclusions}

A newly developed image-before-etch HMT, where imaging was performed before and after etching, was used to identify hydrogen diffusion paths in multi-phase, fine grained TRIP steel. The image-before-etch method is 
critical to clearly observe hydrogen migration paths and correlate the locations with the microstructure in fine grained AHSS TRIP steel. Application of the traditional image-after-etch method to surfaces with significant topography, introduced by etching, leads to hydrogen locations that are inconsistent with room temperature hydrogen diffusivities in multi-phase TRIP steel.

Acknowledgments The authors are grateful for the support of the Advanced Steel Processing and Products Research Center, an industry/university cooperative research center at the Colorado School of Mines.

\section{References}

1. I.M. Bernstein, The role of hydrogen in the embrittlement of iron and steel. Mater. Sci. Eng. A 6(1), 1-19 (1970)

2. J. Hirth, Effects of hydrogen on the properties of iron and steel. Metall. Trans. A 11(6), 861-890 (1980)

3. J.A. Ronevich, J.G. Speer, D.K. Matlock, Hydrogen embrittlement of commercially produced advanced high strength steels. SAE Int. J. Mater. Manuf. 3(1), 255-267 (2010)

4. T.P. Perng, C.J. Altstetter, Hydrogen effects in austenitic stainless steels. Mater. Sci. Eng. A 129(1), 99-107 (1990)
5. K. Ichitani, M. Kanno, Visualization of hydrogen diffusion in steels by high sensitivity hydrogen microprint technique. Sci. Technol. Adv. Mater. 4(6), 545-551 (2003)

6. J. Ovejero-Garcia, Hydrogen microprint technique in the study of hydrogen in steels. J. Mater. Sci. 20(7), 2623-2629 (1985)

7. K. Ichitani, S. Kuramoto, M. Kanno, Quantitative evaluation of detection efficiency of the hydrogen microprint technique applied to steel. Corros. Sci. 45(6), 1227-1241 (2003)

8. H.K. Yalçì, D.V. Edmonds, Application of the hydrogen microprint and the microautoradiography techniques to a duplex stainless steel. Mater. Charact. 34(2), 97-104 (1995)

9. S.S. Chen, T.I. Wu, J.K. Wu, Effects of deformation on hydrogen degradation in a duplex stainless steel. J. Mater. Sci. 39(1), 67-71 (2004)

10. K. Ichitani, M. Kanno, S. Kuramoto, Recent development in hydrogen microprint technique and its application to hydrogen embrittlement. ISIJ Int. 43, 496-504 (2003)

11. J.A. Ronevich, B.C. De Cooman, J.G. Speer, E. De Moor, D.K. Matlock, Hydrogen interactions with austenite in pre-strained TRIP steel. Metall. Trans. A (2012). doi:10.1007/s11661-011-1075-3

12. A. Nagao, S. Kuramoto, K. Ichitani, M. Kanno, Visualization of hydrogen transport in high strength steels affected by stress fields and hydrogen trapping. Scripta Mater. 45(10), 1227-1232 (2001)

13. A.K. De, J.G. Speer, D.K. Matlock, Color tint-etching for characterization of complex microstructures in multiphase steels. Appl. Mater. Proc. 161(2), 27-30 (2003)

14. W.C. Luu, J.K. Wu, The influence of microstructure on hydrogen transport in carbon steels. Corros. Sci. 38(2), 239-245 (1996) 